BUSINESS

\title{
Missing the mark
}

\section{Genetic tests to detect cancer are feasible. But with researchers drowning in a sea of biomarkers and little financial incentive to get the tests on the shelves, the idea is floundering. Virginia Gewin reports.}

T he genomic revolution brought in its wake the promise that it would be possible to detect - and arrest - the earliest signs of cancer. By tapping in to molecular biomarkers, initial signs of disease would be seen and effective treatments implemented. That promise remains resolutely unfulfilled.

In laboratories around the world, the discovery of candidate biomarkers continues apace. But the process of developing them into diagnostic tests is stalling. No early detection diagnostic test has so far been approved by regulatory bodies. Industry observers say a major problem is that there is no way to validate candidate biomarkers with the certainty that would merit their development into a marketable test. And the sheer number of candidates makes it hard to select which ones should be more fully developed.

For their part, doctors want tests that identify the proper treatment course for individual patients. It is unclear whether they will adopt biomarker tests that serve only as diagnostics and don't point the way to specific therapies.

"Biomarkers are only as good as their ability to link to the treatment or pathology of the disease," says Harvey Pass, a clinician working on detection biomarkers for mesothelioma at New York University Medical Center.

Back in 2000, the US National Cancer Institute established the Early Detection Research Network (EDRN) in a bid to bridge the validation gap. The network sought to establish some of the infrastructure needed to test and validate candidate biomarkers. This is complicated by the fact that diagnostic tests often need to feature several markers to ensure that they are statistically significant.

\section{On trial}

In its draft assessment, the network reports movement on several fronts. Of the thousands of candidate biomarkers so far discovered, the EDRN is backing 120 in various stages of development. Among these, biomarkers for five cancers - mesothelioma, and liver, bladder, prostate and lung cancers - are in their third and final phase of development, and are being tested for effectiveness in large-scale human trials.
One of the EDRN's collaborators is Cangen Biotechnologies of Baltimore, Maryland, which hopes to put the first DNA-based early detection test for bladder cancer on the market. Cangen is confident that its test - a panel of 15 DNA segments - can identify tumours well ahead of existing diagnostics. But although detection may come a little earlier, a patient's primary treatment option remains the same: surgery. That means that the overall impact on patient survival rates may be relatively small.

For Eddy Agbo, Cangen's research director, linking the test to new drug therapies that could combat these early tumours is the next step forward. But in the
such therapies, there isn't a huge absence of such therapies, there isn't a huge
incentive for doctors and the health-care insurers that pay for most medical services in the United States to buy the tests.

Given its resources, the pharmaceutical industry would seem to be well placed to take candidate diagnostics tests through to approval. But rather than early detection tests, the industry seems more keen on using biomarkers to pinpoint patient suitability for treatment with particular drugs. There have been isolated successes for this approach, notably the targeting of the breast-cancer drug Herceptin, made by Genentech in South San Francisco, California.
Herceptin targets patients who over-express a particular receptor and had sales of US $\$ 1.3$ billion last year.

Everyone is looking for a dramatic demonstration of biomarker success, says Sam Hanash, a molecular biologist at the Fred Hutchinson Cancer Research Center in Seattle, Washington. The bottleneck isn't the lab-based discovery science, but the ability to efficiently weed through the overwhelming number of candidate genes, proteins and even microRNAs that could be clinically useful. "It's like the Wild West - anyone can stake claim to a biomarker," says Hanash.

\section{Setting standards}

The EDRN has done what it can to find some of the most promising markers and get them into trials. The network has made available cancerous and control reference tissue, serum and blood samples for lung, breast, ovarian, prostate and colon tumours. These can be used as the first step in validation by scientists claiming a biomarker. The EDRN has also established quality-control for validation testing, a standardized system for presenting data, and, with other groups at the National Cancer Institute, has established the beginnings of large-scale human biosample collection.

These steps are necessary, specialists say, but may not be sufficient to bring biomarker tests to market. The EDRN provides a valuable but incomplete resource, says Mike Gillette, a proteomics researcher at the Broad Institute in Cambridge, Massachusetts. Further validation steps require large-scale trials on broader populations, which are expensive and so temper industry interest.

In July, the US Food and Drug Administration (FDA) addressed industry concerns

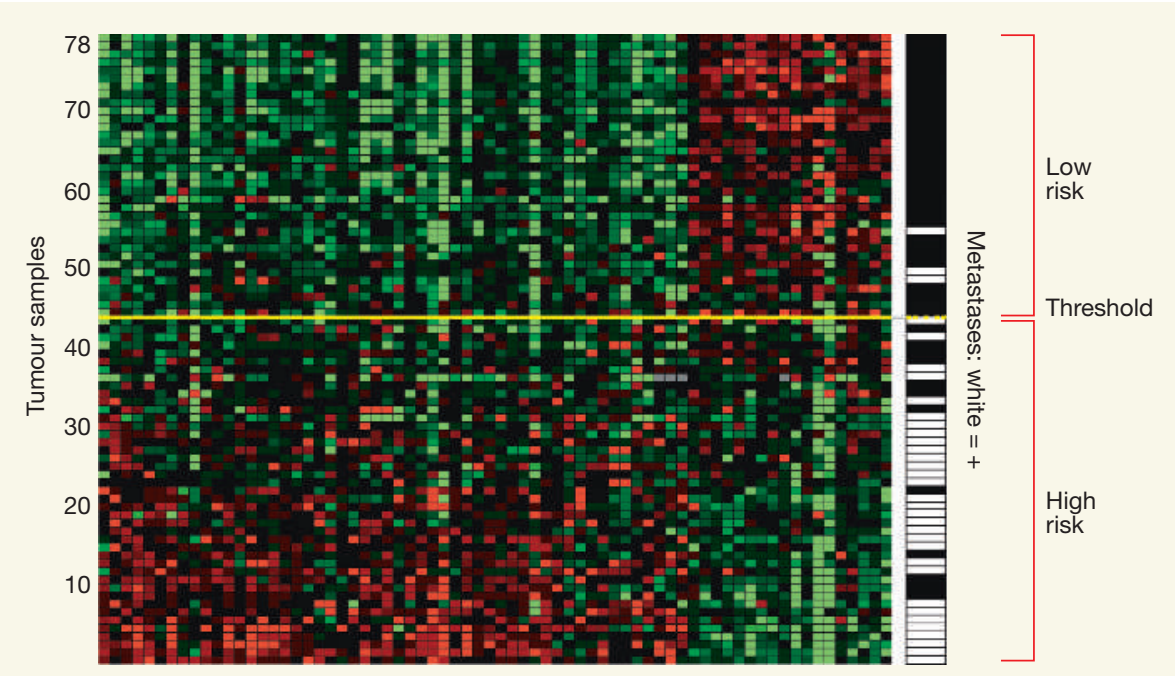

Genetic tests, such as this one for breast cancer, can help to tune treatments. 
about the approval process by publishing draft guidelines for tests that use multiple biomarkers. Yet to be finalized, the regulations make an important distinction: class II tests, which are merely diagnostic or prognostic, can be validated using trials on tissue-bank samples. But class III tests, which are those that also indicate which therapies should be used, must undergo a more costly trial in which patients are tracked in the future.

The shallow pockets of most diagnostic testing companies can't support the multimilliondollar costs of even the class II trials. "You need pushers and drivers to develop biomarkers," says Pat Price, a clinical researcher for Cancer Research UK at the University of Manchester, "and those are usually the drug companies." Price predicts that the drug industry will become steadily more interested in biomarkers as it comes to see its future in more segmented markets for drugs effective in particular genetic subpopulations. She says that, in general, the middle ground between biomarker discovery and the clinic is neglected by funding agencies and so is unattractive to researchers.

The EDRN is an exception - but it spends its \$28-million budget validating only diagnostic or prognostic biomarkers. According to Pass in New York, collaboration with the network has been invaluable to develop early detection biomarkers for mesothelioma. $\mathrm{He}$ and others are now pushing for the EDRN to develop biomarkers for therapeutic prediction to complete the continuum of treatment.

Murray Robinson, a senior vice-president at AVEO Pharmaceuticals in Cambridge, Massachusetts, says that the success of Herceptin has made parts of the pharmaceutical industry sit up and take notice.

Larger companies, such as Roche of Switzerland, are vigorously exploring the co-development of biomarkers for particular diseases and drugs to treat them. That approach may have diminished the firm's interest in stand-alone tests developed by smaller companies. René Bernards, chief scientific officer of Agendia, a cancer-diagnostics company in Amsterdam, is disappointed by the lack of interest drug companies have shown in his firm's test. MammaPrint, which predicts the likelihood of breast-cancer recurrence, is the first multigene prognostic test to be approved by the FDA.

"If it's clear that the FDA is going to regulate this space of biomarkers, and ours is the only company to clear a multigene biomarker through the FDA, you would think a few large pharmaceutical companies would want to collaborate," he says. But Bernards is still waiting for someone to bite; and patients may wait many years yet for the true dawning of the age of personalized medicine.

\section{IN BRIEF}

SCORING HIGH Pharmaceuticals have surpassed computing and electronics hardware as the industry sector declaring the biggest total global investment in research and development (R\&D), according to an annual scoreboard published by the European Commission. The scoreboard indicates that industrial R\&D by the world's top 1,000 companies - thought to account for $85 \%$ of industrial R\&D between them - surged ahead last year by $10 \%$, to $€ 372$ billion (US $\$ 527$ billion). US drugmaker Pfizer is now the biggest spender, investing $€ 5.8$ billion, whereas the largest-spending European company is DaimlerChrysler, at $€ 5.2$ billion.

DRUG PRODUCTION Ugandan president Yoweri Museveni has commissioned what his government says is the first factory in Africa that will produce full combinations of antiretroviral drugs for the treatment of AIDS. Quality Chemical Industries, a Ugandan drug importer, and Indian drug company Cipla will operate the plant, which is expected to start production early next year. The plant will also produce combinations of antimalarial drugs.

AIMING LOW Changes in UK rules on capital-gains tax could hit the emergence of London's Alternative Investment Market (AIM) as a popular global venue for listing science- and technology-based companies (see Nature 447, 367; 2007), some analysts say. The British finance minister, Alistair Darling, announced on 9 October that capitalgains tax would be levied at a flat rate of $18 \%$ from next April. Many investors on the AIM currently pay only $10 \%$. But the announcement had no immediate effect on the prices of stocks listed on the AIM.

\section{MARKET WATCH}

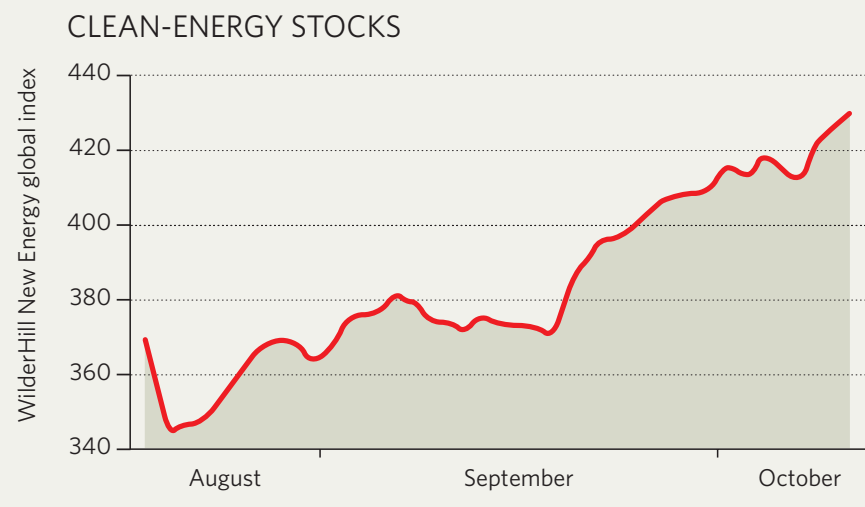

Stocks in clean-energy companies rebounded to reach all-time highs in the past two months, after dipping with the rest of the stock market earlier in the summer.

The WilderHill New Energy Global Innovation Index (symbol NEX on the American Stock Exchange) now stands at almost twice its level at the beginning of 2006 - reflecting the new-found tendency of mainstream investors to take 'alternative energy' stocks seriously.

A closer look at the index shows a mixed pattern, says Robert Wilder, whose California-based consultancy WilderShares co-compiles the index with New Energy Finance of London.

In particular, investors have realized that biofuels based on corn (maize) will not expand as rapidly as had been hoped, given growing concerns about rising food prices and the suitability of corn as a feeder fuel. Biofuels stocks are near to their lowest point in the past year, Wilder notes, even as the index hit a new high on growing investor confidence in wind and solar-power companies. Wilder notes that many of the solar companies, in particular, are starting to perform like regular industrial firms in a rapidly expanded market, rather than as exotic start-ups. "The 'alternative' label is dropping off," he says

There's clearly been a flood of money into stocks in these areas but, Wilder thinks, opportunities remain in subsectors that have so far been less fashionable, such as geothermal power and companies that specialize in energy efficiency. In the stock markets, at least, "efficiency hasn't been discovered yet", he says.

Colin Macilwain 